\title{
RHEUMATOLOGY
}

\section{Sports injuries in children: should we be concerned?}

\author{
P J Helms
}

This is the fourth article in a series on rheumatology.

Department of Child Health, University of Aberdeen, Foresterhill, Aberdeen AB25 2ZD

Correspondence to: Professor Helms.
Despite worrying evidence that British children, like their parents, ${ }^{1}$ lead a predominantly sedentary life, ${ }^{23}$ concerns continue to be expressed for those children who do take part in organised sport and who may be involved in intensive training from an early age. ${ }^{4}$ Injuries of all types in childhood account for a large part of the workload of accident and emergency departments and result in a significant number of deaths per year. However, deaths from sporting activity in childhood are rare, and are mainly associated with cardiovascular conditions such as hypertrophic cardiomyopathy and congenital coronary artery anomalies in boys. ${ }^{6}$ However, there remains the possibility that children who undertake intensive training and frequent competition may suffer the long term consequences of acute and overuse injury in later life. Over the past two decades it has been noted that the age of athletes taking part in competition and regular training in sports such as tennis, swimming, and gymnastics has been reducing. ${ }^{4}$ This is a likely consequence of the 'catch them young' philosophy, the widespread belief that in order to achieve international success at senior level it is necessary to start intensive training well before puberty. ${ }^{4}$ These concerns have led to the issuing of guidelines for sports participation by children ${ }^{8}$ and warnings of increasing risk of acute and overuse injuries as children change from varied free play to the repetitive demands dictated by the specialised pattern of movement imposed by a single sport at high level. ${ }^{9}{ }^{10}$

\section{What injuries?}

During the growth spurt, adolescents are particularly vulnerable to injuries. ${ }^{9}$ Studies in the early 1980s suggest that between 3 and $11 \%$ of school age children were injured each year while taking part in some form of sports activity, ${ }^{11}{ }^{12}$ with more recent studies suggesting a higher figure of $22 \% .^{13}$ As might be expected boys are more commonly affected than girls. ${ }^{12}{ }^{14}$ Physical characteristics may play a part, for example joint laxity is associated with ligamentous injury while tightness of ligaments is more correlated with meniscal injuries and ankle, shoulder, and wrist sprains. ${ }^{15}$ In adolescence, transient loading to joints may also result in so called exertion injuries which usually resolve over a period of six months without any specific treatment. ${ }^{16}$ Other so called intrinsic risk factors have been identified including age, sex, and personality. Extrinsic factors that have been identified include type of sport, level of competition, playing surfaces, weather conditions, and provision of protective clothing or equipment. ${ }^{17}$ Matching of opponents is also an important factor. Viewed largely in terms of chronological age, youth sport is often banded by the child's birth date. However, this does not take biological age differences into account. The potential competitive inequality and increased risk of injury associated with such mismatches are especially evident in contact and collision sports. ${ }^{18}$ Although minor soft tissue injuries and cuts and abrasions make up the majority of injuries, more serious injuries including acute fractures and stress fractures do occur. It has been suggested that a uniquely vulnerable time for fractures occurs at the age of peak height increase when there may be an imbalance between muscle strength and relative bone strength. ${ }^{1920}$ Several studies have reported the occurrence of bone fractures in children involved in a range of sports. The huge variation from $1 \%$ in weight training ${ }^{21}$ to nearly $70 \%$ in wrestlers ${ }^{22}$ highlights one of the problems in identifying the true prevalence of sports injury. These problems include different definitions of injury, whether the study was retrospective or prospective, the intensity of exposure to exercise, and the ability and skill of the individual. The latter issue is of considerable significance as it has been suggested that the reported low injury rates in elite young athletes may be attributed to this factor. ${ }^{23}$ The immature musculoskeletal system of the growing child results in different patterns of injury from those found in mature adults. Particularly vulnerable sites include the growth plate, the joint surfaces, and sites of musculotendinous insertion. ${ }^{24}$

Stress fractures in childhood are rare, although the pattern is thought to be different from those found in older children and adults, with most of the studies on stress fractures being performed in young track and field athletes in whom the lower limb and its attachments are particularly vulnerable. A review of a four year experience of 368 such injuries in 324 athletes found that running accounted for 
almost three quarters of all such injuries, with ball games showing a very low incidence of under $7 \% .^{25}$ There are a wide range of possible injuries of the skeletal system in young athletes which are more the concern of the orthopaedic surgeon or accident and emergency specialist and these have been extensively reviewed. ${ }^{26}$

\section{Definitions and risks}

As there is no clear definition of what constitutes a sports injury, ${ }^{27}$ it is not surprising that the published prevalence by sport varies widely. Definitions of injury may influence the prevalence and incidence as will the retrospective or prospective nature of the study. The severity is also open to debate as it can be defined as an event causing the athlete to miss a practice session, a competition, or a defined period ranging from a few hours to days or weeks. In a large prospective study of over 450 athletes from four sports, soccer, gymnastics, tennis, and swimming, it was found that injury rates in boys and girls were very similar, with the exception of female gymnasts in whom a higher prevalence was found. ${ }^{23}$ This could have been due to sex differences or to the fact that the majority of coaches are men and that girls were being given less appropriate advice than their male counterparts. However, this prospective study was different from many others in that it assessed elite athletes who were identified by coaches as having international potential. Injury rates were low in this study and were predominantly minor. ${ }^{23}$ This may have been because of the selection of a talented group of youngsters or because of the more expert coaching in such an elite group. However, in a prospective study of Danish soccer players aged $12-18$ years in which a similar definition of injury was used, an incidence of 3.7 injuries per 1000 hours of soccer played was found which was of a similar low order. ${ }^{28}$ Low rates of injury in the more gifted children could also be explained by selection of individuals with a more robust musculoskeletal system. To clarify the issue of sports related injury, future studies should consider using recently developed indicators, including type of injury, nature and duration of treatment, time lost from sport, school absenteeism, permanent damage, and financial costs. ${ }^{29}$

\section{Sports specific?}

Very few prospective data have been reported for groups of intensively training young people, which prompted the Sports Council to support the training of young athletes (TOYA) study in the mid-1980s. Details of this study and the broad conclusions have been described. ${ }^{30}$ This longitudinal study surveyed the incidence of injury retrospectively for two consecutive years. Athletes ranged in age from 8 to 18 years and included representatives from soccer, gymnastics, swimming, and tennis. Of the 453 athletes the average incidence of injury in a year was identified as 54 per 100 athletes, ${ }^{23}$ which was slightly higher than 39 injuries per 100 athletes found in a large American survey. ${ }^{31}$ Although there are no prospective random community samples of injuries in children engaging in nor- mal day to day activity, considering the very high rate of injury and use of children's accident and emergency departments, the rates above do not look particularly high. As might be expected the lowest incidence of injury was found in swimmers $(37 \%)$ and the highest in soccer players (67\%). Gymnasts were nearly eight times more likely to be injured in both training and competition than swimmers, whereas soccer players were more likely to be injured during competition than training, a pattern that probably reflects the contact nature of the sport and relatively longer periods spent in competition than training. Swimmers and to a lesser extent male tennis players sustained a substantial number of injuries in activities outside their main sport, and it was likely that most of these occurred during sporting activity in school. There is evidence that combined factors such as poor playing fields, inadequate protective equipment, and insufficient supervision by instructors with limited knowledge may contribute to the incidence of injury in school sport. ${ }^{32}{ }^{33}$ Increasing participation in school sport is one of the "health of the nation' targets, and, if a parallel increase in injuries is to be avoided, attention will have to be given to adequate facilities, equipment, and training for those supervising this activity.

\section{Intensive training}

Concern has been expressed that the intensity of training is likely to increase the risk of injury. In the TOYA study, as in other similar studies, it was difficult to clearly identify what constituted intensive training. As might be expected, perceived intensity varied considerably between sports but also between coaches within the same sport. In the TOYA study, hours trained per week was used as a criterion of intensity. When children who were considered to be exposed to intensive training, using thresholds agreed by their coaches, were separated from the remainder, no significant differences were found between the injury rates of high and low intensity trainees. ${ }^{34}$ It would therefore seem that intensive training in elite athletes with good facilities and with experienced coaches is less likely to result in significant injury than less well supervised sporting activity in schools and ad hoc clubs. Of the 492 injuries reported over the two year period in the TOYA study, just over one third were identified as overuse injuries, the remainder being acute. However, there are no long term data available apart from anecdotal reports from individuals with severe overuse injuries from sports such as gymnastics, tennis, and soccer. When overuse injuries occur they tend to be more severe, with an approximate doubling of days off training as a consequence. ${ }^{34}$

\section{Counting the cost}

The majority of injuries are dealt with in the first instance by physiotherapists, and, somewhat surprisingly from the TOYA study, it was found that a large portion of these injuries were treated privately, resulting in considerable costs for families involved. ${ }^{34}$ Although some sporting bodies such as the British Amateur Gymnastic 
Association buys medical insurance for its members, only a small minority of individuals took up this option. For those children involved in regular sporting activity there is a potential for a significant financial burden to be added to the financial support required in travelling to and from sporting events. This may well reduce the likelihood of sustained sporting activity in talented young people and is an important issue that needs to be addressed.

In all the detailed studies of reports of injury in specific sporting groups it must be remembered that accidents are extremely common in children and that serious injury and death are much more likely to occur outside the gymnasium, swimming pool, or away from the sports field. Indeed it is much more likely that children are at greater risk of being seriously injured riding their bicycles to sporting activities, skateboarding, roller blading, or travelling in the family car! Although well supervised sporting activity has a low risk of serious injury and is likely to have quite significant health benefits for those taking part, very little information is available on the long term consequences of overuse injury, which could be a concern for such groups as gymnasts and soccer players. Most injuries are acute and self limiting but those overuse injuries that do occur can result in lengthy periods of enforced inactivity and may have long term consequences for adult musculoskeletal health. Set against these possible long term concerns is the proved benefit of vigorous exercise in adolescence and early life ${ }^{35}$ and the observation that world class male athletes enjoy an extended life expectancy. ${ }^{36}$

1 Allied Dunbar National Fitness Survey. A report on activity patterns and fitness levels. London: Sports Council and Health Education Authority, 1992

2 Armstrong N. Children are fit but not active. Education in Health 1989;7:28-32.

3 Riddoch C, Savage JM, Murphy N, Cran GW, Boreham C. Long term health implications of fitness and physical activity patterns. Arch Dis Child 1991;66:1426-33.

4 Maffulli N, Helms P. Controversies about intensive training in young athletes. Arch Dis Child 1988;63:1405-7.

5 Skolnick, AA. Health pros want new rules for girl athletes. FAMA 1996;275:22-4

6 Van Camp SP, Bloor CM, Mueller FO, Cantu RC, Olson HG. Non-traumatic sports death in high school and college athletes. Med Sci Sports Exerc 1995;27:641-7.

7 Malina RM, Meleski BW, Shoup RF. Anthropometric body Malina RM, Meleski BW, Shoup RF. Anthropometric body composition and maturity characteristics of selected

8 Committee on Sports Medicine. Recommendations for parCommittee on Sports Medicine. Recommendations for par-

9 Micheli LJ. Overuse injuries in children's sport: the growth factor. Orthop Clin North Am 1983;14:337-60.
10 Sahlin Y. Sports accidents in childhood. Br 7 Sports Med 1990;24:40-4.

11 Gallagher SS, Finison K, Guyer B, Goodenough S. The incidence of injuries among 87,000 Massachusetts children and adolescents: results of the 1980-81 statewide childhood injury presentation program surveillance system. $\mathrm{Am}$ f Public Health 1984;8:318-24.

12 Zaricznyj B, Shattuck LJM, Mast TA, Robertson RV, D'Elia G. Sports-related injuries in school-aged children. $A m \mathcal{F}$ Sports Med 1980;8:318-24.

13 Backx FJG, Beijer HJM, Bol E, Erich WBM. Injuries in high risk persons and high risk sports: a longitudinal study of 1818 school children. Am F Sports Med 1991;19:124-30.

14 Jacobsson B. Sports accidents among children and teenagers. A one year study of incidence and severity in a Swedish rural municipality. Scandinavian fournal of Sports Sciences 1986;8:75-9.

15 Marshall JL, Tischler HM. Screening for sports. N Y State $\mathcal{f}$ Med 1981;9:68-75.

16 Kujala UM, Kvist M, Osterman K. Knee injuries in athletes. Review of exertion injuries and retrospective study of outpatient sports clinic material. Sports Med 1986;3:447-9.

17 Malina RM, Beunen G. Matching of opponents in youth sports. In: Bar-Or O, ed. The child and adolescent athlete: the encyclopaedia of sports medicine. Oxford: Blackwell Science, 1996:202-13.

18 Lysens R, Stererlynck A, Van den Auwele Y, Lefevre J, Renson L, Claessens A, Ostyn M. The predictability of sports injuries. Sports Med 1981;1:6-10.

19 Bailey DA, Wedge JH, McCulloch RG, Martin AP, Bernhardson SC. Epidemiology of fractures of the distal end of the radius as associated with growth. $\mathcal{F}$ Bone foint Surg 1989;71A:1225-31.

20 Hagino $H$, Yamamoto $K$, Teshima $R$, Kishimoto $H$, Nakamura T. Fracture incidence and bone mineral density of the distal radius in Japanese children. Arch Orthopaedic Trauma Surg 1990;109:262-4.

21 Risser WL, Preston D. Incidence and causes of musculoskeletal injuries in adolescents training with weights. Pediatric Exercise Science 1989;1:84.

22 Snook GA. Injuries in intercollegiate wrestling. A five year study. Am F Sports Med 1982;10:142-4.

23 Baxter-Jones A, Maffuli N, Helms P. Low injury rates in elite athletes. Arch Dis Child 1993;68:130-2.

24 Gerrard DF. Overuse injury and growing bones. The young athlete at risk. $B r \mathcal{F}$ Sports Med 1993;27:14-8.

25 Hulkko A, Orgva S. Stress fractures in athletes. Int $\mathcal{F}$ Sports Med 1987;8:221-6.

26 Maffulli N, Baxter-Jones ADG. Common skeletal injuries in young athletes. Sports Med 1995;19:137-49.

27 Van Mechelen W, Hlobil H, Kemper HCG. Incidence, severity, aetiology and prevention of sports injuries. Sports Med 1992;14:82-9.

28 Poulsen T, Freund K, Madsen F, Sandvej K. Injuries in high-skilled and low-skilled soccer: a prospective study. $\mathrm{Br}$ f Sports Med 1991;25:151-3.

29 Backx FJG. Epidemiology of paediatric sports-related injuries. In: Bar-Or O, ed. The child and adolescent athlete: the encyclopaedia of sports medicine. Oxford: Blackwell Science, 1996;163-72.

30 Baxter-Jones ADG, Helms PJ. Effects of training at a young age. A review of the training of young athletes (TOYA) study. Pediatric Exercise Science (in press).

31 Garrick JG, Requa RH. Injuries in high school sports. Pediatrics 1978;61:465-9.

32 Micheli LJ, Klein JD. Sports injuries in children and adolescents. Br F Sports Med 1991;25:6-9.

33 de Brujn JV, Keizers S. Sports injury registration: the Fysion Blesreg System. Br F Sports Med 1991;25:124-8.

34 Jones A. Training of young athletes study (TOYA) and sports injuries. London: Sports Council, 1992.

35 Shinton R, Sagar G. Lifelong exercise and stroke. BM7 1993;307:231-4

36 Sarna S, Sahi T, Koshenvuo M, Kaprio J. Increased life expectancy of world class male-athletes. Med Sci Sports Exerc 1993;25:237-44. 